\title{
IMPROVING MECHANICAL PROPERTIES OF CONCRETE USING CARBON FIBERS COMPOSITES
}

\author{
Ali, Y. R. M. H. ${ }^{(1)}$ and Alrifaie, M. M. S. ${ }^{(1)}$
}

1) The Public Authority for Applied Education and Training

\begin{abstract}
The study aimed at improving the mechanical properties of reinforced concrete using carbonated fiber, containing different percentages of fiber. using high range water reducing agent (SP) with $8 \%$ silica fume (SF) and $8 \%$ high reactivity Metakaolin (HRM), as a partial replacement by weight of cement, on the behavior of light weight concrete (LWA) concrete is also studied. This investigation was carried out using several tests. These tests were workability fresh and hardened density, compressive strength, splitting tensile strength and modulus of rupture. Tests were performed for specimens at ages of $(7,28,60,90$ and 180$)$ days.

On the basis of results of this investigation the following conclusions may be deducted:

- It is possible to produce a light weight aggregate carbon fiber concrete with a dry density ranged between (1820) to $(1950) \mathrm{Kg} / \mathrm{m}$ the addition of (SF) or (HRM) does not affect the density significantly.

- The required dosage of superplasticizer (SP) for carbon fiber LWAC increases with increasing the percentage volume fraction of fiber. The useful dosage range is (to 4-8\%)

- The addition of carbon fiber to (HRM and SF) light weight concrete increases slightly the compressive strength. Also the compressive strength increases with increasing volume fraction of carbon fiber by about (1.15 $\%, 0.49 \%$ and $2.20 \%)$ for mixes containing carbon $(3 \%, 3.75 \%$ and $4.5 \%)$ respectively, after (28) day.

- The tensile strength of (LWAC) mixes increases by about $(173,242$ and $296 \%)$ for mixes containing carbon fiber with volume fraction $(3 \%, 3.75 \%$ and $4.5 \%$ ) respectively, after (28) day.
\end{abstract}


- An improvement in modulus of rupture is observed when the mineral admixtures (HRM) or (SF) and (SP) are used with (LWAC) mixes containing carbon fiber. Maximum increase is found to be(321.7\%)when using (LWAC)mixe with (Sp) containing (4.5\%) of carbon fiber by volume, after (28) day.

Key Words: Mechanical properties- Concrete- carbon fiber - Silica fume Metakaolin.

\section{INTRODUCTION}

Due to the necessities of low weight and high strength materials, it is required to find out the suitable substitute with low cost. Short fibres composites are the most commonly used as reinforcements to improve the mechanical performance of ceramics, metals and polymers. When compared to continuous fibres reinforced composites, short fibres reinforced composites can be easily processed with affordable cost. The most the important factors in the short fibres reinforcement are fibre dispersion and the fibre aspect ratio.

The homogeneous fibre dispersion is the most important factor to enhance the mechanical properties concrete mixes In this investigation short carbon fibers are spread manually and its uniformity is checked periodically during test.

Despite the great partial importance of fiber reinforced light weight aggregate concrete ((LWAC) in construction field, very limited amount of work has been carried out to investigate the mechanical properties of fiber reinforced (LWAC) containing chemical and mineral admixtures. However, there has been many research work on the mechanical characteristics of carbon fiber reinforced normal concrete. 
The tensile and flexural strength increase with increased of fiber content (from 2 to $10 \%$ ) by volume. The handling and the fabrication create some problems at volume fraction above $10 \%$. And a uniform dispersion of discontinuous carbon fiber can be achieved by use of the condensed silica fume with proper dose of super plasticizer. (FDOT, 2017)

Fiber orientation and distribution effected on the behavior of carbon fiber reinforced concrete. A substantial increase in impact and fracture energy are observed in proportion to volume fraction of fiber used (Ohama, 1983).

A beneficial effect of integrating total light weight into carbon fiber reinforced cement composite. Significant improvement in compression strength, tensile strength and cement shredding factor can be obtained by incorporating the total light weight in the compound. (Gutjit, et al., 2016)

An investigation studied the influences of using short pitch based carbon fiber $(0.2 \%$ by volume) together with dispersant chemical agents and silica fume on properties of concrete. The increase in compressive strength, modulus of rupture and flexural toughness by about $22 \%, 18.5 \%$ and 20.5\% respectively has been observed. (Pu, et al., 1993)

In an other paper a combined use of fiber and silica fume is recommended. (Pu, et al., 1997)

The short carbon fiber cement matrix composite exhibited considerable tensile and modulus of rapture properties, low drying shrinkage, low thermal conductivity and high corrosion resistance. (Chung, 1999) 
Ultra high performance concrete specimens show fracture toughness three to four times more than those of high performance concrete specimens containing fibers of the same length. (Nigel, et al., 2001)

Researchers from all over the world are focusing on improving the mechanical properties of the concrete with incorporating wide range of supplementary material such as fibers, steel wires and nano particles due to the increased use of concrete. The use of steel wires, fibers and nano particles, is not only effective but also provides insight into the nanostructure of these composites.

This investigation studies the mechanical characteristics of carbon fiber reinforced light weight aggregate concrete, containing different percentages of fiber. The effect of using high range water reducing agent (SP) with $8 \%$ silica fume (SF) and 8\% high reactivity Metakaolin (HRM), as a partial replacement by weight of cement, on the behavior of (LWA) concrete is also studied.

\section{EXPERIMENTAL PROGRAM:}

For production of LWAC mixes, light weight aggregate, porcelain crushed stone was used as a lightweight aggregate and natural sand as fine aggregate chemical fiber, mineral fibers and carbon fibers were also used in this study. 


\section{MATERIALS}

1).Cement: Ordinary Portland cement (Type I) was used in all mixes throughout this investigation. It was stored in air - tight plastic containers to avoid exposure to atmospheric conditions. The percentage oxide composition indicated that the adopted cement comforms to the Kuwait specification, (Standard Specification for Concrete Aggregates) , [KWS GSO ASTM C33 / C33M:2015]

2) Fine aggregate: Normal weight natural sand from AL-Jahra region was used as fine aggregate. The grading of the sand conformed to the requirement of Kuwait specification (3). The sulfate contant, specific gravity and the absorption of the used sand were $(0.08 \%),(2.6),(2.2 \%)$ respectively.

3).Coarse aggregate : Local naturally occurring light weight aggregate of porcelinite stones was used as coarse aggregate. It was brought in large lumps from the State Company of Geological Survey. The lumps were firstly crushed into smaller sizes manually by means of a hammer in order to facilitate the insertion of lumps through the feeding openings of the crusher machine. The crushed aggregate is grouped to different sizes and then the required coarse aggregate was prepared to conform to ASTM C192M-02 specification.

4).Superplasticizer (SP): A superplasticizer type (GLENIUM51) based on modified polycarboxylic either was used throughout this investigation. (It is free from chlorides and complies with ASTM C494M/04 types A and F. 
5).High reactivity metakaolin (HRM): High reactivity metakaolin (HRM) is reactive aluminosilicate pozzolana formed by calcining purified kaolinite at specific temperature. The activity index of the used (HRM) is 165, it comprises nearly 88 percent of $(\mathrm{SiO} 2+\mathrm{A} 12 \mathrm{O}+\mathrm{fe} 2 \mathrm{O} 3)$ which conforms to ASTM C618-03 class N pozzolana according to specification for natural and calcined pozzolana. The specific surface area and the specific gravity of the used HRM were $1900 \mathrm{~cm}^{2} / \mathrm{gm}$ and 2.62 , respectively.

6).Carbon Fiber: High performance high strength carbon fiber system for was used in this investigation. it was brought as aloom roll $0.5 \mathrm{~m}$ wide. It has a high impact resistance, very good tensile strength and elastic modules elasticity. Also it has a very good chemical resistance under variety of environmental conditions exposure conditions. Table (1) shows the general properties of the used carbon fibers.

\section{CONCRETE MIXES}

Concrete mixes containing porcelinite aggregate as light weight aggregate should have an oven-dry density $<2000 \mathrm{~kg} / \mathrm{m}^{3}$ and a concrete compressive strength >15 MPa to produce structural (LWAC). These mixes were designed in accordance with ACI commitee 211-2-81. The details of these mixes are given in Table (2).

\section{DETERMINATION OF THE WORKABILITY}

Workability of all tested mixes was measured by the V.B. test method and slump test. The water - cement ratio and dosage of (SP) were adjusted to obtain almost similar workability, slump $(100+10) \mathrm{mm}$ or V.B (4-5) sec for 130 
all reference mixes. Table (2) shows the optimum dosage of (SP) for various types of tested concrete mixes.

PREPARATION, CASTING AND CURING OF SPECIMENS: Steel molds were used for casting all specimens. They were cleaned and oiled before casting. The fresh concrete was placed inside the molds with approximately equal layers of $50 \mathrm{~mm}$ and compacted by means of vibrating table. Care was taken to avoid segregation of mixes. After the top layer had been compacted, it was smoothed, then the mold covered with nylon sheets for 24 hours to prevent evaporation of water so as to avoid the plastic shrinkage cracks. After 24 hours the specimens were demolded and completely immersed in tap water until the time of testing.

\section{TESTING PROGRAMS}

1. Unit weight: The unit weight of fresh and hardened concrete samples were measured according to ASTM C29/C29M-97 and ASTM C567 specifications, respectively.

2. Compressive strength: Compressive strength tests were conducted using (100) mm cubes using an electrical testing machine with a capacity of $2000 \mathrm{KN}$ at loading rate of $15 \mathrm{MPa}$ per minute. This test was determined according to B.S. 1881: part 116: 1984.The average of three cubes was adopted for each test. The test was conducted at ages of $(7,28,60,90$ and 180) days.

3. Splitting tensile strength: Splitting tensile strength test was performed according to ASTM C496/C496 M-04 using of $(150 \times 300)$ mm cylinder. 
The test was conducted at age of $(7,28,60,90$ and 180) days. The average splitting tensile strength of three cylinders was adopted.

4. Modulus of rupture: Modulus of rupture of concrete was measured on $(100 \times 100 \times 400) \mathrm{mm}$ specimens according to ASTM C78-02. The prisms were subjected to two- point loading. Specimens were tested at age of $(7,28,60,90$ and 180) days.

\section{RESULTS AND DISCUSSIONS}

1. Unit weight: The obtained results of the fresh and 28 days air dry density of all types of concrete mixtures are presented in Table (2) and Fig (1). Results show that the 28 day air dry densities of light weight concrete mixes produced from local naturally occurred porcelinite aggregate are conformed to the requirement of ACI 213-R-87. For structural (LWAC), the air dry densities should be ranged between (1820-1950)kg, however all concrete mixes conform to the requirements of class I (SLWAC) according to RILEM classification which limits the maximum density to $2000 \mathrm{~kg} / \mathrm{m}^{3}$. Results show that the superplasticizer (LWAC) mixes without fibers have higher density than fiber reinforced (LWAC) containing mineral admixture (SF) and (HRM). This is attributed to the superplasticizer effect which reduces the water content of the mixes and consequently produces matrix with less air voids. The percentage of difference in 28 days air dry unit weight of (SP) carbon fiber concrete for all mixes is shown in Fig. (1). It is evident that (SF-SP) and (HRM-SP) concrete have lower density than those of (SP) concrete mixes. Also, 
results show that the hardened unit weight of carbon fiber concrete decreases slightly as the volume fraction of fiber is increased.

2. Compressive strength :The compressive strength development at various curing ages for all types of mixes is presented in Table (3) and Fig (2). Test results illustrate that in general, reference (LWAC) and carbon fiber reinforced concrete specimens exhibited continuous development in strength up to 180 days of curing. There is a considerable improvement in strength for mixes containing superplasticizer. This behavior was due to the high reduction in (w/c) ratio (up to $38.09 \%$ ) and to the well dispersion of cement. The addition of ( $8 \%$ by wt.) (SF) or (HRM) as a partial replacement of cement improved the concrete strength. The use of (HRM) increases compressive strength more than when using (SF) in carbon fiber reinforced concrete, there was a slight increase in the compressive strength with increasing the fiber volume fraction, unless the fiber volume is so high leading the air voids content to become excessively high. The air voids tends to have a negative effect on the compressive strength, therefore the use of (SP), (SF) or (HRM) enhances the compressive strength .

3. Splitting tensile strength : Results of splitting tensile strength of various types (LWA) concretes cured in tap water up to 180 days are demonstrated in Table (4) and Fig (3). Results indicate that reference and carbon fiber reinforced (LWA) concrete specimens exhibited continuous increase in splitting tensile strength with increasing curing age. The incorporation of (SP) in (LWAC) leads to higher splitting tensile strength compared to their corresponding reference concrete at all ages. This behavior is mainly 
attributed to the significant reduction in the capillary porosity of the cement matrix as well as to the good dispersion of the cement grains throughout the mix. At age of 28 day and above (LWAC) with (SF) or (HRM) shows improvement in splitting tensile strength over the reference concrete. This is attributed to the pozzloanic reaction of (HRM) and (SF) which reacts with the calcium hydroxide liberated during the hydration of cement and contributes to the densification of the concrete matrix, thereby strengthening the transition zone and reducing the microcracking leading to a slight increase in splitting tensile strength. The percentages increase in splitting tensile strength of (LWAC) mixes at 180 days curing age measured relative to their refrence mix are shown in Fig (3).

The tensile strength of the fiber concrete mixes increases with the increase of fiber volume content. This is due to the nature of binding effect of fiber available in concrete matrix. The control batch specimens containing no fiber failed suddenly once the concrete cracked, while the fiber reinforced concrete specimens were still intact together. This shows that the carbon fiber reinforced concrete has the ability to absorb energy in the post- cracking state. Table (5) illustrates the comparision of percentage difference in splitting tensile strength for carbon fiber reinforced concrete to its control batch. For example the percentage increase in tensile strength for (LWAC) mixes containing carbon fiber by volume fraction of $(3 \%, 3.75 \%, 4.5 \%)$ were (189.6\%, 206.04\% and 230.2\%) respectively. (SP- SF) and (SP- HRM) carbon fiber (LWAC) exhibited a slight increase in splitting tensile strength with high volume fraction of carbon fiber $(3,3.75$ and 4.5$) \%$. The 
percentages increase are shown in Table (5). The percentages increase in splitting tensile strength measured relative to (SP) for carbon fiber (LWAC) with fiber volume $(3 \%, 3.75 \%$ and 4.5$)$ were $(8.79 \%, 11.07 \%$ and 15.04$)$ respectively for (SP-SF) and for (SP- HRM) the percentage increase were $(18.46 \%, 19.84 \%$ and $20.83 \%)$ respectively.

4. Modulus of rupture: The influence of curing age on the modulus of ruptur all types of (LWAC) specimens are presented in Table (6) and Fig (4). Results demonstrate that all concrete specimens exhibited considerable increase in flexural strength with increasing curing ages. The improvement in modulus of rupture is attributed to the reduced capillary porosity of cement matrix caused by the high reduction in water content of the mix, and due to the significant improvement in the transition zone The modulus of rupture trend for carbon fiber varies as the volume fraction of fiber is increased. It is found that, the modulus of rupture increases as the fiber volume fraction is increased. The concrete specimens containing no carbon fibers are cracked and failed in a brittle manner when strain in concrete reached its ultimate value.

However, fiber reinforced concrete also cracked at ultimate strain, but the section is still capable to carry the load well after the initiation of the first crack . Test results indicated that, the modulus of rupture of carbon fiber concrete specimens are five times that of the control specimens. The addition of (SP- HRM) or (SP-SF) to carbon fiber reinforced concrete effect significantly the flexural strength. Test results shows a clear increase in flexural strength compared to concrete specimens with out (SF) or (HRM) 
and also showed an increase in modulus of rupture with increasing curing age.

\section{CONCLUSIONS}

\section{On the basis of results of this investigation the following conclusions may} be deducted:

- It is possible to produce a light weight aggregate carbon fiber concrete with a dry density ranged between (1820) to $(1950) \mathrm{Kg} / \mathrm{m}$ the addition of (SF) or (HRM) does not affect the density significantly.

- The required dosage of superplasticizer (SP) for carbon fiber LWAC increases with increasing the percentage volume fraction of fiber. The useful dosage range is (4 to $8 \%$ )

- The addition of carbon fiber to (HRM and SF) light weight concrete increases slightly the compressive strength. Also the compressive strength increases with increasing volume fraction of carbon fiber by about (1.15 $\%, 0.49 \%$ and $2.20 \%)$ for mixes containing carbon $(3 \%, 3.75 \%$ and $4.5 \%)$ respectively.

- The tensile strength of (LWAC) mixes increases by about (173, 242 and $296 \%)$ for mixes containing carbon fiber with volume fraction $(3 \%, 3.75 \%$ and $4.5 \%$ ) respectively.

- An improvement in modulus of rupture is observed when the mineral admixtures (HRM) or (SF) and (SP) are used with (LWAC) mixes containing carbon fiber. Maximum increase is found to be(321.7\%)when using (LWAC)mixe with (Sp) containing (4.5\%) of carbon fiber by volume. 


\section{REFERENCES}

Chung D. (1999): "Carbon Fiber cement - Matrix composites", TANSO, 190, 300-312.

FDOT (2017): Fiber reinforced polymer guidelines (FRPG), FDOT structure manual, florida department of transportation, Environmental and Infrastructure Engineering, (4), U.S.A, 33-75.

Gurjit. Singh., \& Jaspal Singh., (2016): "Materials improve tensile strength of concrete at micro level ", International Journal of civil, Structural, Environmental and Infrastructure Engineering, (6), (3), $30-45$.

Nigel. G. S., \& Mohammed, M. (2001): "Enhancing fracture toghness of high-performance carbon fiber cement composites", ACI material Journal, 98, (2), 125-141.

Ohama. Y ., \& Amano, M. \& Endo, M. (1983): " Properties of carbon fiber reinforced cement with silica fume", Concrete International, (3), $58-62$.

Puwoei C. \& Chung D. (1993), "Concrete reinforced with up to -(0.2-0.1)\% of short carbon fiber composites", Smart Materials and Structures Journal, 24, (1), 147-155.

Puwoei, C. \& Chung, D., (1997), Micro structural and mechanical effects of latex, methylecellulose, and silica fume carbon fiber reinforced cement", ACI ASTM C496/C496 M-04 ASTM C496/C496 M-04 Material Journal, 94, (2), 230-261.

Table(1): Physical properties of carbon fiber used in this investigation

\begin{tabular}{|c|c|}
\hline Grade & 300HS \\
\hline Weight $\left(\mathrm{g} / \mathrm{m}^{3}\right)$ & 300.00 \\
\hline Design thickness $(\mathrm{mm})$ & 0.17 \\
\hline Tensile strength desig $\left(\mathrm{kgf} / \mathrm{cm}^{2}\right)$ & 35.50 \\
\hline Fiber length $(\mathrm{mm})$ & 19.00 \\
\hline Carbon content $(\%)$ & $98 \mathrm{wt}$ \\
\hline Specific gravity & 1.90 \\
\hline Elongation at break $(\%)$ & 1.40 \\
\hline
\end{tabular}


J. Environ. Sci.

Institute of Environmental Studies and Research - Ain Shams University

Table(2): Details of the mixes used through out this investigation

\begin{tabular}{|c|c|c|c|c|c|c|c|}
\hline \multirow{2}{*}{ Mix } & \multirow{2}{*}{$\begin{array}{c}\text { \%of } \\
\text { fiber by } \\
\text { volume }\end{array}$} & \multirow{2}{*}{$\begin{array}{c}\text { w/c } \\
\text { ratio } \\
\text { by wt. }\end{array}$} & \multirow{2}{*}{$\begin{array}{c}\text { (SP)\% } \\
\text { by wt. } \\
\text { of } \\
\text { cement }\end{array}$} & \multicolumn{2}{|c|}{$\begin{array}{c}\text { Mineral } \\
\text { Admix by wt. } \\
\text { of cement \% }\end{array}$} & \multirow{2}{*}{$\begin{array}{c}\text { Fresh } \\
\text { density } \\
\mathbf{k g} / \mathbf{m}^{3}\end{array}$} & \multirow{2}{*}{$\begin{array}{c}\text { Unit } \\
\text { weight } \\
\text { Air dry } \\
\text { density } \\
28 \text { days } \\
\text { kg/m } / \mathrm{m}^{3}\end{array}$} \\
\hline & & & & $\begin{array}{c}\text { (SF) } \\
\%\end{array}$ & $\begin{array}{c}\text { (HRM) } \\
\%\end{array}$ & & \\
\hline MR 0 & 0 & 0.42 & - & - & - & 1985 & 1868 \\
\hline MR 1 & 0 & 0.26 & 4.00 & - & - & 2015 & 1918 \\
\hline MR 2 & 0 & 0.26 & 4.50 & 8 & - & 2006 & 1909 \\
\hline MR 3 & 0 & 0.26 & 5.00 & - & 8 & 21010 & 1914 \\
\hline 3MR1 & 3.00 & 0.31 & 6.00 & - & - & 1976 & 1909 \\
\hline $3.75 \mathrm{M} 1$ & 3.75 & 0.31 & 6.50 & - & - & 1988 & 1922 \\
\hline $4.5 \mathrm{MR} 1$ & 4.50 & 0.31 & 7.00 & - & - & 2014 & 1931 \\
\hline $3 \mathrm{MR} 2$ & 3.00 & 0.31 & 6.50 & 8 & - & 1954 & 1884 \\
\hline $3.75 \mathrm{M} 2$ & 3.75 & 0.31 & 7.00 & 8 & - & 1971 & 1898 \\
\hline $4.5 \mathrm{MR} 2$ & 4.50 & 0.31 & 7.50 & 8 & - & 1998 & 1916 \\
\hline 3 MR3 & 3.00 & 0.31 & 7.00 & - & 8 & 1963 & 1896 \\
\hline $3.75 \mathrm{M} 3$ & 3.75 & 0.31 & 7.50 & - & 8 & 1978 & 1906 \\
\hline $4.5 \mathrm{MR} 3$ & 4.50 & 0.31 & 8.00 & - & 8 & 2006 & 1920 \\
\hline
\end{tabular}

Table(3): Compressive strength test results for carbon fiber (LWAC) mixes

\begin{tabular}{|c|c|c|c|c|c|}
\hline Type of & \multicolumn{5}{|c|}{ Compressive strength $\mathbf{N} / \mathbf{~ m m}^{\mathbf{2}}$} \\
\cline { 2 - 6 } Batch & 7 days & 28 days & 60 days & 90 days & 180 days \\
\hline \hline MR 0 & 19.8 & 29.7 & 36.3 & 37.6 & 39.2 \\
MR 1 & 27.73 & 40.83 & 41.67 & 42.43 & 43.35 \\
MR 2 & 30.12 & 41.56 & 42.22 & 43.77 & 44.65 \\
MR 3 & 27.31 & 42.51 & 43.37 & 44.12 & 54.23 \\
3MR1 & 26.13 & 40.36 & 40.71 & 41.02 & 41.32 \\
3.75 MR1 & 28.93 & 41.03 & 4.74 & 42.87 & 43.95 \\
4.5 MR1 & 30.71 & 41.73 & 43.36 & 44.41 & 45.73 \\
3 MR2 & 26.17 & 40.41 & 41.54 & 42.32 & 43.78 \\
3.75 MR2 & 28.53 & 41.15 & 42.51 & 43.73 & 44.63 \\
4.5 MR2 & 29.56 & 42.83 & 43.67 & 44.71 & 45.23 \\
3 MR3 & 24.67 & 41.13 & 42.22 & 43.35 & 44.35 \\
3.75 MR3 & 30.71 & 42.32 & 43.32 & 44.71 & 46.53 \\
4.5 MR3 & 31.13 & 43.37 & 44.71 & 47.77 \\
\hline
\end{tabular}


Table(4): Splitting tensile strength test results for carbon fiber (LWAC) Mixes

\begin{tabular}{|c|c|c|c|c|c|c|}
\hline \multirow{2}{*}{$\begin{array}{c}\text { Type of Mix } \\
\text { Batch }\end{array}$} & $\begin{array}{c}\text { Fiber } \\
\text { volume\% }\end{array}$ & $\mathbf{7}$ days & $\mathbf{2 8}$ days & $\mathbf{6 0}$ days & $\mathbf{9 0}$ days & $\begin{array}{c}\mathbf{1 8 0} \\
\text { days }\end{array}$ \\
\cline { 2 - 7 } & 0 & 1.7 & 1.97 & 2.05 & 2.15 & 2.18 \\
MR 0 & 0 & 2.14 & 2.54 & 2.63 & 2.81 & 2.98 \\
MR 1 & 0 & 2.18 & 2.59 & 2.62 & 2.7 & 2.82 \\
MR 2 & 0 & 2.22 & 2.63 & 2.69 & 2.78 & 2.88 \\
MR 3 & 3.00 & 4.92 & 6.15 & 6.98 & 7.79 & 8.63 \\
3MR1 & 3.75 & 5.12 & 7.23 & 7.43 & 8.63 & 9.12 \\
3.75 MR1 & 4.50 & 5.83 & 7.87 & 7.93 & 8.74 & 9.84 \\
4.5 MR1 & 3.00 & 5.04 & 6.87 & 7.71 & 8.89 & 9.13 \\
3 MR2 & 3.75 & 5.23 & 7.05 & 8.25 & 9.43 & 10.31 \\
3.75 MR2 & 4.50 & 5.89 & 8.13 & 9.27 & 10.42 & 11.321 \\
4.5 MR2 & 3.00 & 5.01 & 7.02 & 8.15 & 9.24 & 10.31 \\
3 MR3 & 3.75 & 5.78 & 7.89 & 8.95 & 9.82 & 10.93 \\
3.75 MR3 & 4.50 & 5.99 & 8.63 & 9.46 & 10.73 & 11.89 \\
4.5 MR3 &
\end{tabular}

Table(5): Modulus of rupture test result for carbon fiber (LWAC) mixes

\begin{tabular}{|c|c|c|c|c|c|c|}
\hline \multirow{2}{*}{$\begin{array}{c}\text { Type of Mix } \\
\text { Batch }\end{array}$} & $\begin{array}{c}\text { Concrete Compressive strength N/ mm } \\
\text { \% } \\
\text { \% }\end{array}$ & $\mathbf{7}$ days & $\mathbf{2 8}$ days & $\mathbf{6 0}$ days & $\mathbf{9 0}$ days & $\begin{array}{c}\mathbf{1 8 0} \\
\text { days }\end{array}$ \\
\hline \hline MR 0 & 0 & 2.85 & 3.42 & 3.61 & 3.81 & 3.97 \\
MR 1 & 0 & 3.63 & 4.88 & 5.11 & 5.58 & 5.89 \\
MR 2 & 0 & 3.87 & 5.12 & 5.43 & 5.71 & 5.96 \\
MR 3 & 0 & 3.32 & 5.20 & 5.58 & 5.82 & 6.02 \\
3MR1 & 3.00 & 9.38 & 13.33 & 14.51 & 15.22 & 16.07 \\
3.75 MR1 & 3.75 & 12.95 & 16.72 & 17.32 & 17.93 & 18.45 \\
4.5 MR1 & 4.50 & 14.68 & 19.35 & 19.66 & 20.02 & 20.42 \\
3 MR2 & 3.00 & 8.98 & 13.04 & 14.75 & 15.83 & 16.81 \\
3.75 MR2 & 3.75 & 11.26 & 16.35 & 17.88 & 18.72 & 19.38 \\
4.5 MR2 & 4.50 & 14.02 & 19.23 & 19.99 & 20.43 & 20.81 \\
3 MR3 & 3.00 & 9.02 & 13.85 & 15.82 & 16.33 & 16.99 \\
3.75 MR3 & 3.75 & 11.03 & 16.24 & 18.11 & 18.97 & 19.33 \\
4.5 MR3 & 4.50 & 14.00 & 19.56 & 20.16 & 20.83 & 21.45 \\
\hline \hline
\end{tabular}


J. Environ. Sci.

Institute of Environmental Studies and Research - Ain Shams University

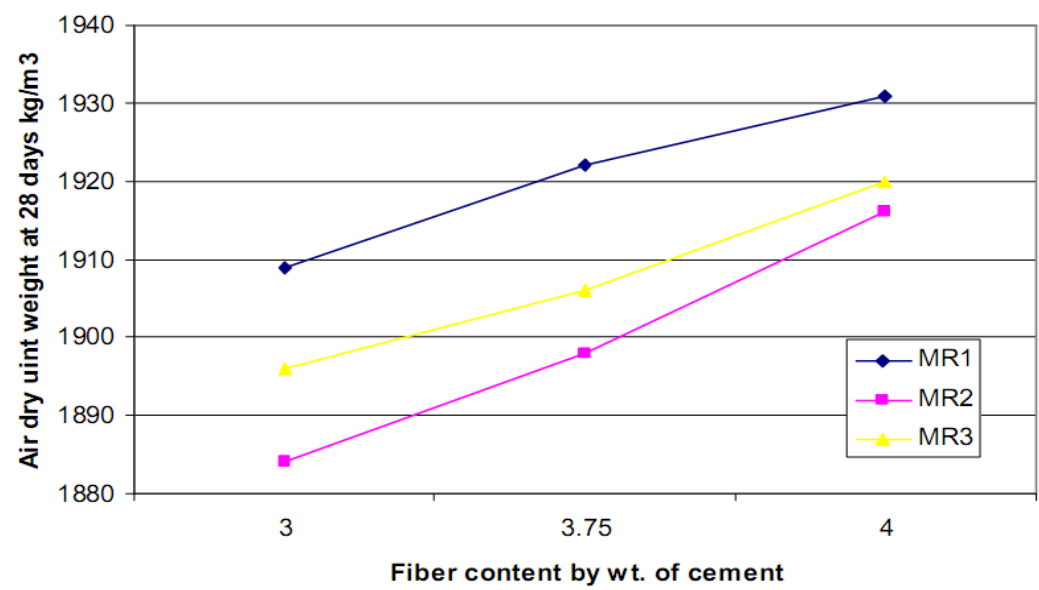

Fig(1): Effect of containing carbon fiber on unit weight of light weight concrete For (MR1,MR2,MR3) mixes 
Ali et al.
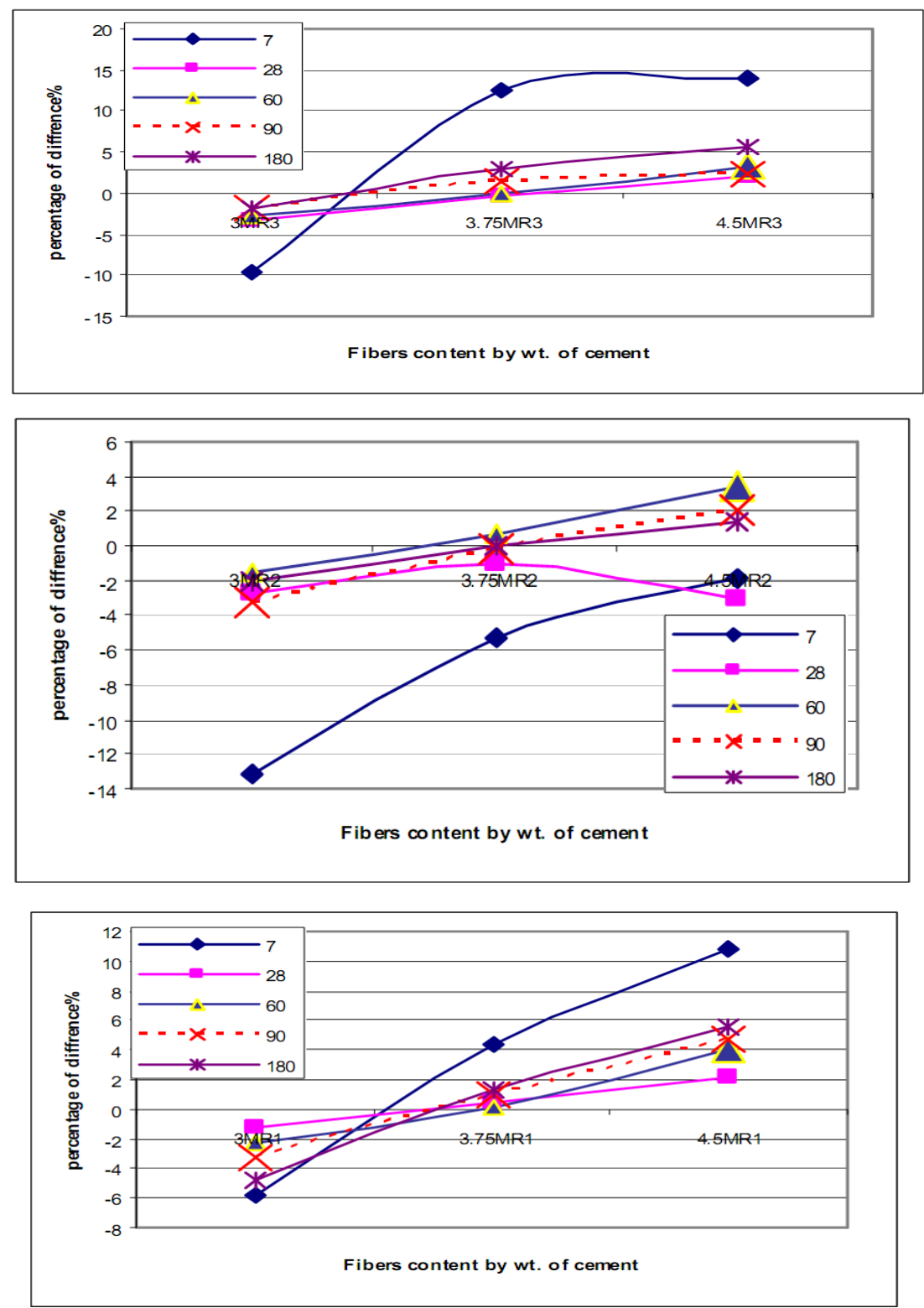

Fig(2): Effect of containing carbon fiber on compressive strength of light weight concrete For (MR1,MR2,MR3) mixes

Vol. 40, No.1, Dec. 2017 
J. Environ. Sci.

Institute of Environmental Studies and Research - Ain Shams University
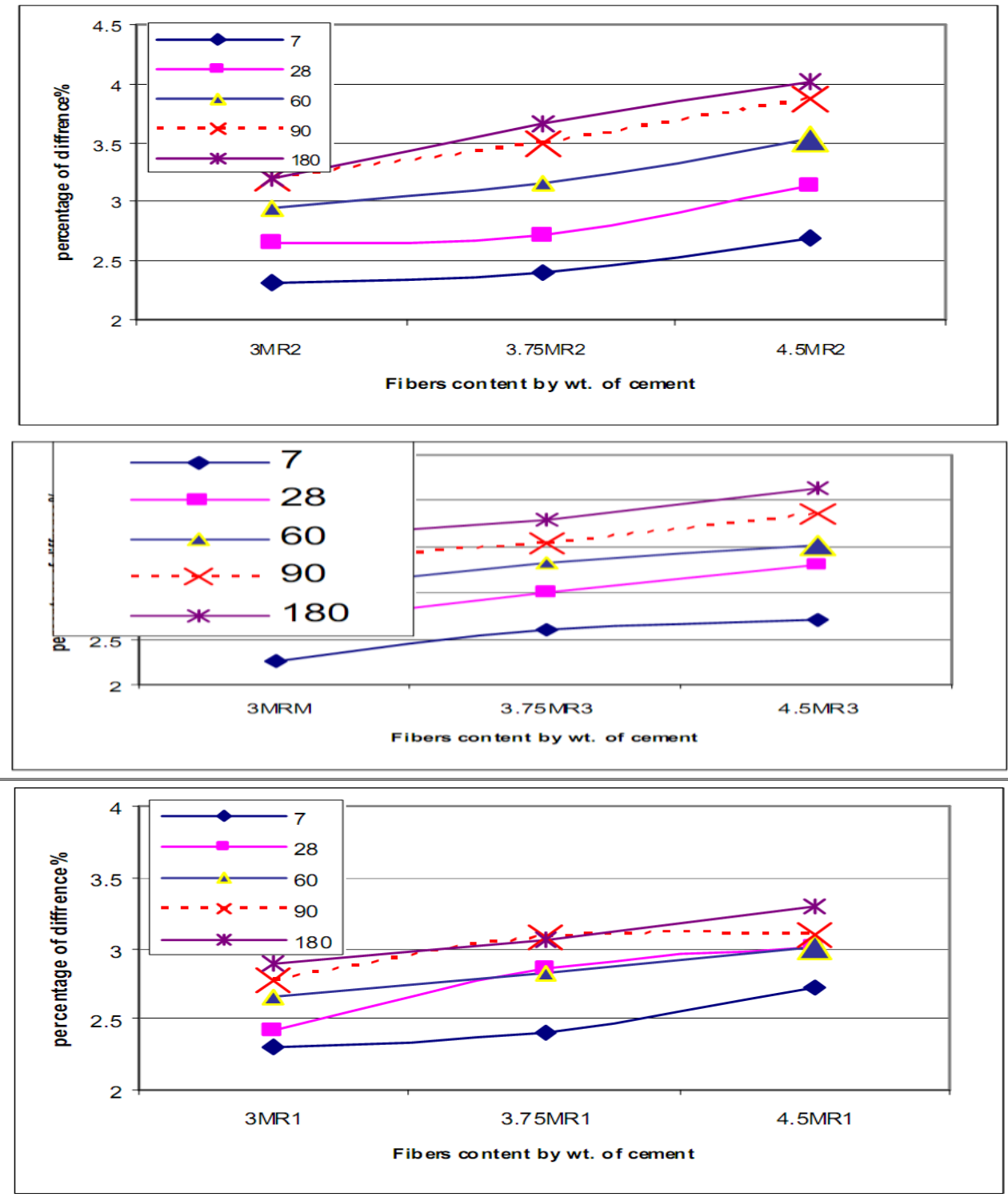

Fig(3): Effect of carbon fiber on splitting tensile strength of light weight concrete For (MR1,MR2,MR3) mixes 
Ali et al.
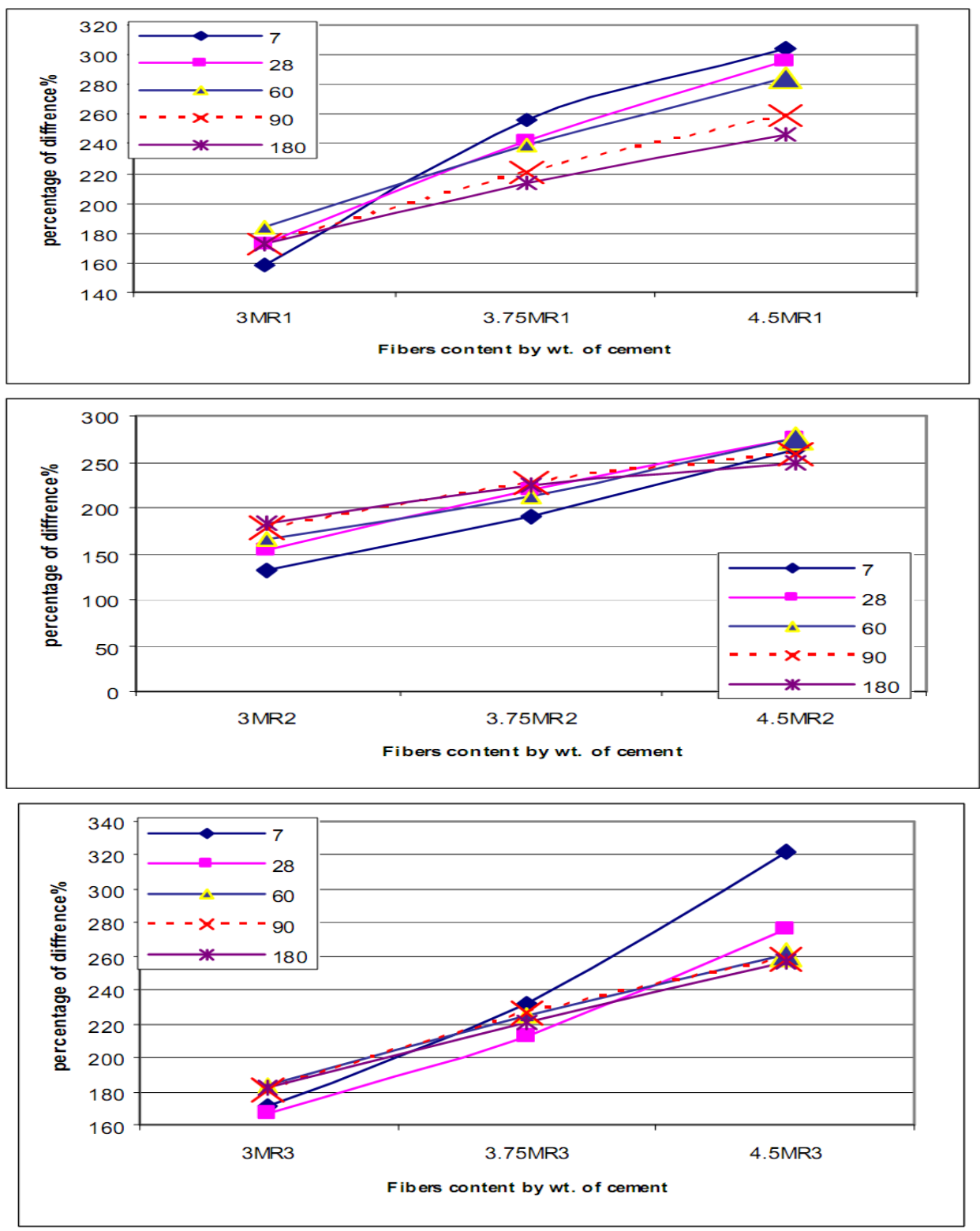

Fig(4): Effect of carbon fiber on modulus of rupture of light weight concrete for (MR1,MR2,MR3) mixes

Vol. 40, No.1, Dec. 2017 


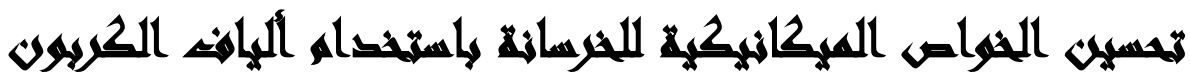

[†]

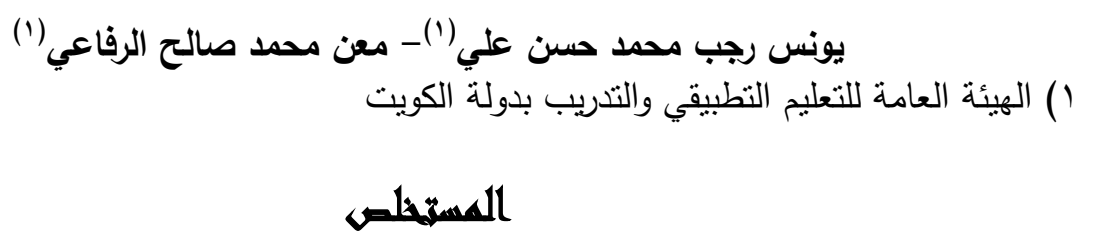

تهدف هذه الدراسة إلى تحسين الخواص الميكانيكية للخرسانة المسلحة بنسب مختلفة من ألياف

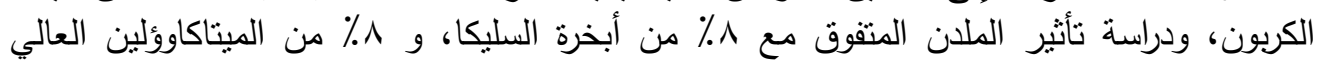

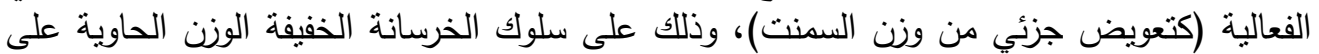

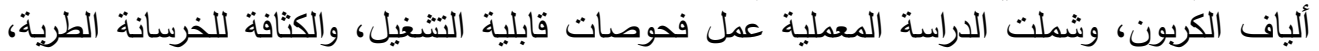

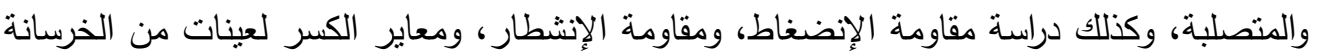

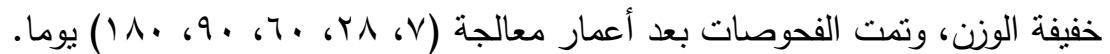

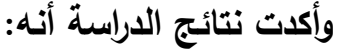

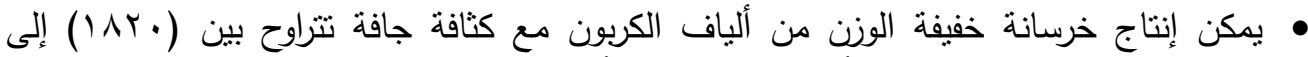

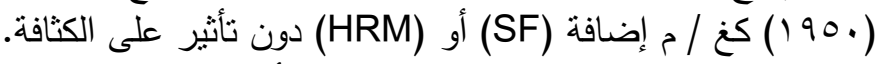

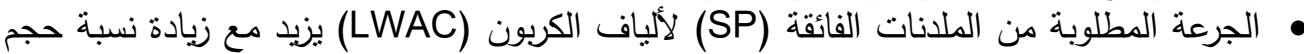

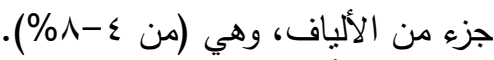

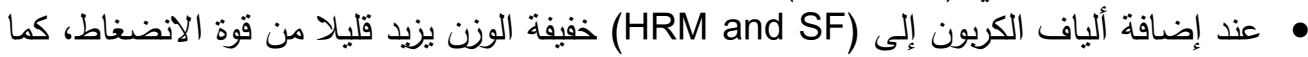

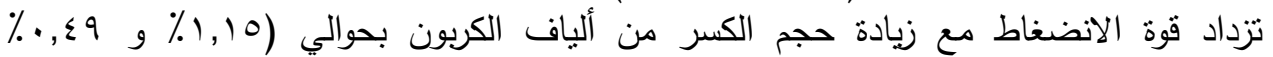

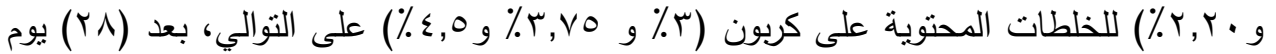

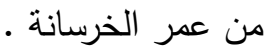

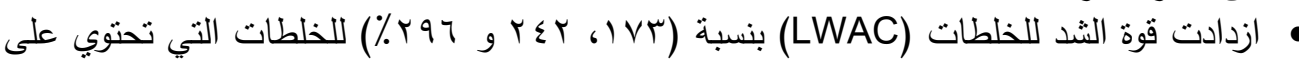

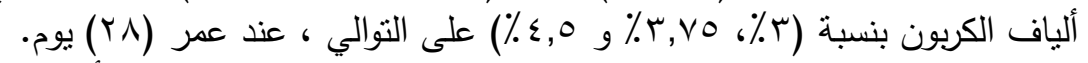

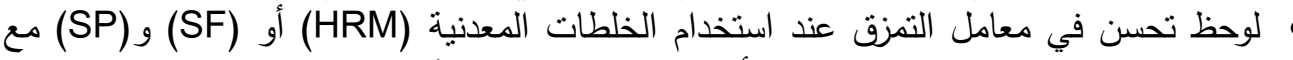

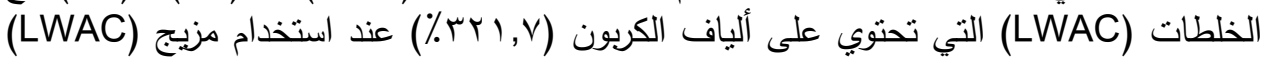

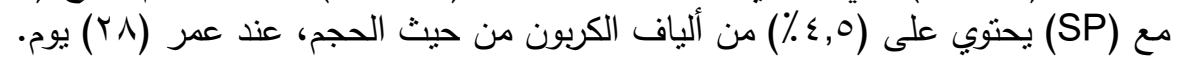

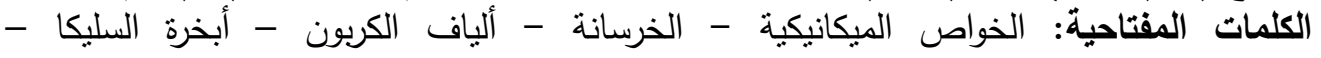
الميتاكاوؤلين. 